\title{
GESTÃO DO CONHECIMENTO NO ENSINO PÚBLICO: UMA AGENDA DE PESQUISA
}

\author{
Caio Pisconti Machado \\ Arthur Gualberto B. da C. Urpia** \\ Leticia Fleig Dal Forno***
}

RESUMO: Esta pesquisa possui como objetivo analisar como os processos organizacionais, na perspectiva da Gestão do Conhecimento (GC), contribuem para a resolução dos problemas específicos da gestão escolar pública. Para isto, utilizou-se de uma abordagem descritiva, de natureza qualitativa, ancorada por uma revisão bibliográfica interdisciplinar, referente às áreas: educação, gestão e gestão do conhecimento. Como resultados de pesquisa, identificou-se que a administração, no contexto da educação, é intrínseca à própria prática educativa e se apresenta como um dos problemas da educação na atualidade. Logo, como resposta a estas demandas, propôs-se, com base na literatura pesquisada, um ciclo de implementação de processos organizacionais em GC, específico para organizações do ensino público. $\mathrm{O}$ ciclo traz aos gestores escolares observações sob como se poderá implementar as práticas organizacionais baseadas na GC. Anexo a esta proposta, sugere-se um roteiro de implementação do ciclo, que descreve como implementar estes processos, adequando-os à realidade do ambiente escolar público.

PALAVRAS-CHAVE: Gestão do conhecimento; Gestão escolar pública; Processos organizacionais.

\section{THE MANAGEMENT OF KNOWLEDGE IN GOVERNMENT-RUN SCHOOLS: A RESEARCH PROGRAM}

ABSTRACT: Current research investigates how organizational processes within the Knowledge Management (KM) contribute towards the solution of specific problems in government-run schools. A descriptive and qualitative approach, based on an

\footnotetext{
Mestrando no Programa de Pós-graduação em Gestão do Conhecimento nas Organizações (PPGGCO) no Centro Universitário de Maringá (UNICESUMAR), Brasil; Bolsista da Coordenação de Aperfeiçoamento de Pessoal de Nível Superior (CAPES), Brasil; E-mail: caiopisconti@gmail.com

** Docente no Programa de Pós-graduação em Gestão do Conhecimento nas Organizações (PPGGCO) no Centro Universitário de Maringá (UNICESUMAR), Brasil; Bolsista produtividade dodo ICETI - Instituto Cesumar de Ciência, Tecnologia e Inovação, Maringá, Brasil.

*** Docente no Programa de Pós-graduação em Gestão do Conhecimento nas Organizações (PPGGCO) no Centro Universitário de Maringá (UNICESUMAR), Brasil; Bolsista produtiidade em pesquisa do ICETI - Instituto Cesumar de Ciência, Tecnologia e Inovação, Maringá, Brasil
} 
interdisciplinary bibliographic review has been elaborated, featuring education, management and knowledge management. Results show that administration within the context of education is intrinsic to educational practice and is one of the main contemporary issues in education. Based on the literature, a cycle of implementation of organizational processes in KM is proposed, which is specific to public schooling. The cycle forwards some observations to school managers on the implementation of organizational practices based on KM. A plan for the cycle's implementation adapted to the public school milieu is suggested.

KEY WORDS: Knowledge Management; Government-run school management; Organizational processes.

\section{INTRODUÇÃO}

Mesmo compreendendo que os entraves e as complexidades enfrentadas pelos profissionais das instituições escolares públicas são abundantes, por meio de pesquisas presentes na área, percebe-se que os profissionais da educação têm sido apontados como um dos responsáveis pela ineficiência escolar. Uma vez que a qualidade da educação e eficiência das escolas é positivamente dependente dos processos de gestão e tomada de decisão que ocorrem nestes ambientes (DAMACENO, 2013; WITTMANN, 2000), esforços têm sido feitos, por meio da publicação de discussões, com o intuito de apontar como os processos de gestão podem colaborar com a promoção do nível de excelência no ensino básico. Apreciando que diversos autores concordam em afirmar que as atividades ligadas à GC proporcionam as organizações maior eficiência na utilização de seus recursos (CAVALCANTI; GOMES, 2001; BATISTA, 2012), fica claro, na medida em que se fazem estas relações entre gestão educacional e nível de qualidade de ensino, que ambos têm intrínsecas relações entre si e constituem importantes fatores a serem analisados no processo de organização escolar.

Logo, torna-se relevante aos gestores de instituições escolares públicas sugestões e ferramentas que os apoiem na implementação de práticas de gestão que deem maior fluidez e eficiência aos processos organizacionais de suas instituições. Neste sentido, a proposta de um ciclo de implementação de práticas dos processos 
organizacionais e a criação de um roteiro de implementação para este ciclo, são explanados neste artigo como importantes contribuições no sentido de resolver alguns dos problemas de gestão encontrados em organizações escolares públicas.

Tomando estes argumentos como base para discussão, questiona-se o seguinte: em quais sentidos a GC, especificamente por meio da área de Processos Organizacionais, auxilia na resolução do problema referente à gestão das escolas públicas? Diante disso, o objetivo geral desta pesquisa é analisar como as práticas de processos organizacionais presentes na GC podem contribuir para a resolução dos problemas específicos da gestão escolar pública. Desta forma, explora-se, nesta lacuna de pesquisa, como as práticas da GC, alinhados na área de processos organizacionais, podem promover a melhoria da qualidade do ensino pelo compartilhamento de experiência e aplicação dos conhecimentos no nível da gestão escolar.

Em relação aos procedimentos metodológicos adotados para este discussão optou-se pela abordagem descritiva. Quanto à natureza da pesquisa, é qualitativa, já que a interpretação dos fenômenos e a atribuição de significados são questões básicas deste processo de pesquisa (SILVA; MENEZES, 2005). Tendo estas implicações, procurou-se por meio de uma revisão bibliográfica interdisciplinar: i) obter informações sobre a situação atual referente ao problema pesquisado, ii) verificar as diversas opiniões a respeito do problema de pesquisa (PRODANOV; FREITAS, 2013; SILVA; MENEZES, 2005), e, finalmente, iii) fomentar a discussão sobre os temas abordados pelos autores, procurando pontos de conversão entre os temas para que soluções concernentes ao problema de pesquisa possam ser descritas.

Desta forma, o presente artigo, além desta introdução, contém mais quatro seções. Na segunda seção encontra-se o referencial teórico. Na terceira seção é apresentada a realidade da gestão pública escolar no Brasil, neste sentido esta abordagem encontra-se direcionada para que se dê atenção especial aos aspectos referentes aos processos organizacionais, que constituem a forma pela qual se faz a gestão das escolas. Na quarta seção, encontra-se a discussão de como a gestão do conhecimento, por meio das práticas concernentes aos processos organizacionais, pode contribuir para diminuir a problemática referente à gestão das escolas públicas. A quinta e última seção será dirigida à apresentação dos comentários finais. 


\section{AS NOVAS PROPOSTAS DA ECONOMIA DO CONHECIMENTO}

O cenário econômico mundial tem passado por significativas transformações tecnológicas, organizacionais, informacionais, institucionais, culturais e sociais interrelacionadas. Igualmente, diferentes designações e descrições têm sido utilizadas para caracterizar a atual nova ordem mundial e o novo padrão econômico emergente, dentre outras, destacam-se as seguintes: economia ou sociedade da informação ou do conhecimento (LASTRES, 1999).

Estes expostos são explicados pelo fato da: (i) informação e o conhecimento passarem a constituir os recursos básicos do crescimento econômico e (ii) tais recursos não serem esgotáveis (LASTRES, 1999). Assim, quando se utilizam corretamente destes insumos, fazendo com que a informação chegue à pessoa certa no momento certo e, com isso, ações e decisões estratégicas possam ser realizadas e mantidas, presencia-se a obtenção de vantagem competitiva. (PORÉM et al., 2012).

Isto contribuiu para a crescente ampliação do mercado e da demanda por setores intensivos em conhecimento e, consequentemente, impôs-se novas bases para o desenvolvimento e para o crescimento econômico. Neste contexto, principalmente o Brasil, passa a ser desafiado a se integrar ao novo modelo (GUIMARÃES, 2011). Assim, as atividades e práticas relacionadas à gestão do conhecimento passaram a auxiliar os gestores no alcance de melhores níveis de eficiência organizacional, por meio do gerenciamento dos conhecimentos presentes em seus recursos humanos.

\subsection{A GESTÃO DO CONHECIMENTO E O SETOR PÚBLICO}

Nas organizações públicas, um significativo número de pessoas não é adequadamente treinado e motivado, não sendo, portanto, incentivado a criar ou inovar, preocupando-se, na maioria das vezes, com processos rotineiros (SOUSA, 2002). Em busca de uma contraposição a esta situação de passividade, Batista (2012) interpõe dizendo que a inovação, junto à aprendizagem organizacional, ajuda a incrementar a capacidade de realização individual, da equipe, da organização e conduz ao aumento da capacidade social. Assim, estes fatores justificam que a administração pública é um contexto de pesquisa importante e específico para a GC, 
pois é necessário mobilizar o melhor conhecimento disponível nas organizações públicas ou fora delas, e por meio da utilização destas práticas concernentes ao tema buscar aumentar a eficiência, melhorar a qualidade e a efetividade social, e para observar os princípios da legalidade, impessoalidade, moralidade, publicidade e eficiência na administração pública (DOURADO, 2006).

Sendo assim, uma agenda de pesquisa específica passa a ser requerida, pois o setor público é organizacionalmente peculiar, por ter diferentes preocupações com relação à eficácia e situações críticas, levando em conta que as decisões em tempo real podem ter consequências de altas perdas ou ganhos, sociais e coletivos (MASSARO et al., 2015). Pela miríade de diferentes conceituações presentes na literatura em relação ao conhecimento e a sua gestão, uma vez que o conceito de gestão do conhecimento ainda está em constante evolução (BATISTA, 2016), alguns pesquisadores se concentraram em aspectos específicos da gestão do conhecimento (SINGH; GUPTA, 2014).

Batista (2012) foi um deles. Em uma iniciativa vinculada ao Instituto de Pesquisa Econômica Aplicada (IPEA), após concluir que os modelos de GC construídos para o setor privado não são adequados para o setor público e que era necessário construir um modelo genérico, holístico, adequado à administração pública brasileira, o pesquisador elaborou um modelo de gestão do conhecimento para a administração pública brasileira. Em seu trabalho, o autor também analisou definições de gestão do conhecimento propostas para a administração pública e adotou uma definição própria de gestão do conhecimento, baseada no enfoque da administração pública brasileira, a saber:

[...] um método integrado de criar, compartilhar e aplicar o conhecimento para aumentar a eficiência; melhorar a qualidade e a efetividade social; e contribuir para a legalidade, impessoalidade, moralidade e publicidade na administração pública e para o desenvolvimento brasileiro (BATISTA, 2012, p. 49).

Este modelo de GC para a administração pública brasileira conta com: i) direcionadores estratégicos da organização: visão de futuro, missão, objetivos estratégicos, estratégias e metas; ii) fatores críticos de sucesso ou viabilizadores da GC, (incluindo: liderança, tecnologia, pessoas e processos); iii) processo de GC 
(baseado em 05 atividades principais: identificar, criar, armazenar, compartilhar e aplicar); iv) ciclo KDCA (respectivamente: corrigir ou armazenar, elaborar o plano de GC, verificar e executar); v) resultados de GC (imediatos e finais) e; vi) partes interessadas na administração pública (o cidadão-usuário e a sociedade). Tendo estes pressupostos como base teórico-conceitual, o presente trabalho considerará como questões de escopo para esta pesquisa, somente um dos viabilizadores críticos para o sucesso da GC para a administração pública brasileira, que é o de processos. Justifica-se esta escolha, pois a sua correta gestão dos processos organizacionais dentro de uma instituição pode impulsionar as atividades organizacionais e gerar valor tanto para as organizações quanto para a sociedade, se alinhados e apoiados pela aprendizagem e inovação organizacional.

\subsection{PRÁTICAS DE PROCESSOS ORGANIZACIONAIS CONTRIBUINDO PARA A EFICÁ- CIA DA GESTÃO PÚBLICA}

Há empresas e instituições que vêm reestruturando seus processos e atividades e vêm definindo e implementando novas estratégias de atuação, desenvolvendo e adotando novos desenhos organizacionais, novos instrumentos e metodologias operacionais (LASTRES, 1999). Entretanto, percebe-se, ainda, que há muitas empresas operando dentro de práticas ultrapassadas, por isso deixam de ser tão eficientes quanto poderiam (FRANCINI, 2002).

Estas reflexões estão ligadas às constatações de Smuts (2009), que afirma que uma empresa com baixos índices de maturidade em seus sistemas de GC corre o risco de perdas financeiras, quando suas habilidades e conhecimentos, encapsulados dentro de sua força de trabalho, saírem pelas portas da empresa e não voltarem para trabalhar no dia seguinte. Nesta perspectiva, resultados de pesquisa sugerem que a estrutura organizacional está positivamente relacionada com a gestão do conhecimento (SOUZA; KURTZ, 2014).

Entende-se, assim, que a estrutura de uma organização baseada no conhecimento deve ser caracterizada por instrumentos e práticas que viabilizem o conhecimento como o principal elo de negócios. Além disto, é essencial que haja, nessa estrutura, um suporte sociotécnico tenaz, a partir da alta gerência, 
perpassando toda a organização, para que, como catalisador, estimule a evolução da gestão do conhecimento (ROSSETTI et al., 2008). Assim, neste trabalho, quando se faz referência às práticas ligadas à estruturação dos processos organizacionais, foca-se em aspectos que funcionam como facilitadores da identificação, criação, compartilhamento, armazenamento e aplicação do conhecimento organizacional (BATISTA, 2012).

\section{A GeSTÃo ESCOLAR PÚBLICA}

Focando mais especificamente no contexto da administração pública escolar, uma vez que este é o contexto definido para esta pesquisa, entende-se que a gestão escolar constitui uma dimensão e um enfoque de atuação que visa promover a organização, a mobilização e a articulação das condições materiais e humanas necessárias para garantir o avanço dos processos socioeducacionais (LÜCK, 2000), percebe-se que este é um processo complexo, dinâmico e evolutivo.

O estudo da escola como organização não é recente, já que desde os anos 30 pesquisa-se sobre a administração escolar. No entanto, mesmo após se passarem décadas e serem elaboradas discussões sobre reformas curriculares, entre outros temas que permeiam a área, notou-se pouca preocupação com os aspectos propriamente organizacionais e técnico-administrativos da escola (LIBÂNEO, 2010). Observa-se, também, que mesmo com mudanças alicerçadas nas novas descobertas na ciência, em especial, na área de administração e nos novos paradigmas emergentes na educação, a escola como organização permaneceu fechada com suas estruturas rígidas e inflexíveis, em dissonância com a realidade (COELHO, 2011). Neste sentido, para melhor entendimento sobre o modo de funcionamento da gestão escolar fazse pertinente utilizar a proposta de Libanêo (2010), que aborda em dois grandes enfoques a maneira como se dá a administração escolar contemporânea.

No primeiro enfoque, a organização escolar é tomada como uma realidade técnica e funciona racionalmente. Assim, esta pode ser planejada, organizada e controlada, de modo a alcançar maiores índices de eficácia e eficiência. As escolas que operam nesse modelo dão muita ênfase à estrutura organizacional e a planos 
de ação que são feitos de cima para baixo (LIBANÊO, 2010). Quanto ao segundo enfoque, verifica-se a organização escolar basicamente como um sistema que agrega pessoas, importando bastante as denominadas interações sociais que acontecem, o contexto sócio-político, entre outras variáveis. Neste caso, a organização escolar não seria uma coisa totalmente objetiva e funcional, mas uma construção social orientada pelos professores, alunos, pais e integrantes da comunidade, sendo esta direcionada aos interesses públicos (LIBANÊO, 2010).

Ressalta-se que, no Brasil, o primeiro modelo de gestão relacionada ao contexto de instituições escolares, que concebe a gestão com base numa estrutura administrativa autoritária, vertical e hierarquizada, ocorre mais comumente nas instituições escolares públicas (LÜCK, 2000). Assim, entende-se que no processo da organização educacional, dispõe-se de elementos compostos por pessoas e processos, que são na verdade instrumentos de ação mobilizados para atingir os objetivos escolares, os quais são o planejamento, organização; direção/coordenação e avaliação (LIBÂNEO, 2010).

\subsection{A GESTÃO DO CONHECIMENTO ESCOLAR}

Verifica-se que o tema gestão escolar torna-se mais carregado de importância e complexidade por meio da compreensão de que a administração no contexto da educação é intrínseca à própria prática educativa, e se constitui enquanto uma dimensão da mesma (WITTMANN, 2000). Neste sentido, abordando o contexto onde as escolas públicas estão inseridas, percebe-se que há incoerência relacionada ao seu modelo de gestão, pois as escolas, como organizações pertencentes à sociedade do conhecimento, ainda são geridas de modo mecanicista, fazendo contraposição ao próprio ambiente onde se situam.

Com relação a isto, tem-se que o modo como é feito o gerenciamento das instituições de ensino é um dos problemas recorrentes encontrados na educação (WITTMANN, 2000). Neste contexto, ao perceber que a gestão está relacionada ao nível de excelência no ensino, Damaceno (2013) oferece importante contribuição sobre que os métodos de gestão, desta vez postulados na perspectiva da GC, na expectativa de melhoria da qualidade do ensino pelo compartilhamento de 
experiência, e aplicação dos conhecimentos. O que pode ser considerado uma resposta ao desnível encontrado entre sociedade do conhecimento e modelo de gestão nas escolas públicas.

Considera-se, a partir desta abordagem, que as escolas públicas precisam buscar iniciativas de gestão bem sucedidas para que sejam efetivados seus processos, de acordo com o nível da qualidade necessária que a sociedade do conhecimento impõe (DAMACENO, 2013). Nesta perspectiva, Aziz (2015) confirma haver existência de um elevado número de pesquisas no campo educacional que abordam aplicações de gestão do conhecimento. Deste modo, evidencia-se, na medida em que se estudam estas contribuições entre gestão educacional e nível de qualidade de ensino, que ambos têm intrínsecas relações entre si e constituem importantes fatores a serem analisados no processo de organização escolar.

\section{O CICLO DE IMPLEMENTAÇÃO DE PROCESSOS ORGANIZACIONAIS EM GC PARA INSTITUIÇÕES PÚBLICAS DE ENSINO}

Feitas estas considerações e abordados os pontos de vista de diversos autores referentes às áreas da gestão, da gestão do conhecimento e da educação, serão analisados pontos de convergência e sugeridos alguns apontamentos. É interessante ressaltar que vários fatores poderiam ser levantados como entraves à educação no Brasil, todavia, para esta pesquisa, preferiu-se tratar especificamente do problema relacionado à gestão, que afeta a eficiência das instituições públicas e a qualidade do ensino a ser prestado. Assim, as escolas, sendo organizações inseridas na sociedade pautada na informação e no conhecimento, necessitam de mudanças complexas nos modelos de como se efetua a sua gestão.

Assim, torna-se relevante a proposta de práticas que orientem o como fazer, já que por meio das práticas de gestão mais contemporâneas, que tem vistas a potencializar a utilização dos ativos informacionais poderá se alcançar níveis maiores de eficiência na gestão das instituições escolares. Sendo assim, as práticas de GC estão dispostas aos gestores não como um produto, uma fórmula, ou como uma forma de estrutura organizacional, mas como orientadoras e direcionadoras do 
como fazer, e inclusive podem ser incorporados pelas organizações públicas sem, no entanto, alterar radicalmente seus padrões estruturais. Destaca-se isto, pois se entende que os padrões sob as quais estas organizações estão estruturadas foram estabelecidos por lei e também porque já foram institucionalizados e legitimados como um molde válido de funcionamento para o setor público. Neste sentido, esta proposta não traz um cunho revolucionário, mas adaptativo.

Colocados estes pontos, propõem-se logo abaixo algumas questões que podem contribuir para melhoria da gestão nas escolas públicas. Recomenda-se isto, longe de pensar que a implementação destas práticas será o único fator que resolucionará todos os problemas da educação no Brasil, pois esta questão é muito mais complexa. Todavia, percebe-se que este pode ser um passo a mais, para se obter maiores níveis de eficiência na prestação de serviços educacionais.

Assim, por meio da reflexão sob qual seria a maneira mais adequada para se implementar as práticas organizacionais, propostas na perspectiva da GC, notou-se que este processo ocorreria mais adequadamente de maneira cíclica, numa sequência de etapas. Neste caso, deu-se ênfase no processo como um todo, não focando práticas isoladas, ou seja, pensou-se num ciclo, de modo que a implementação de uma etapa possibilitasse a ocorrência de outras e assim sucessivamente. Por isto, buscou-se sistematizar o processo e propor um roteiro de implementação das ferramentas ligadas aos processos organizacionais que apoiam a prática da gestão do conhecimento em organizações públicas escolares. O ciclo está disposto logo abaixo na Figura 1 e tem como referência as práticas prescritas no trabalho de Batista et al. (2005).

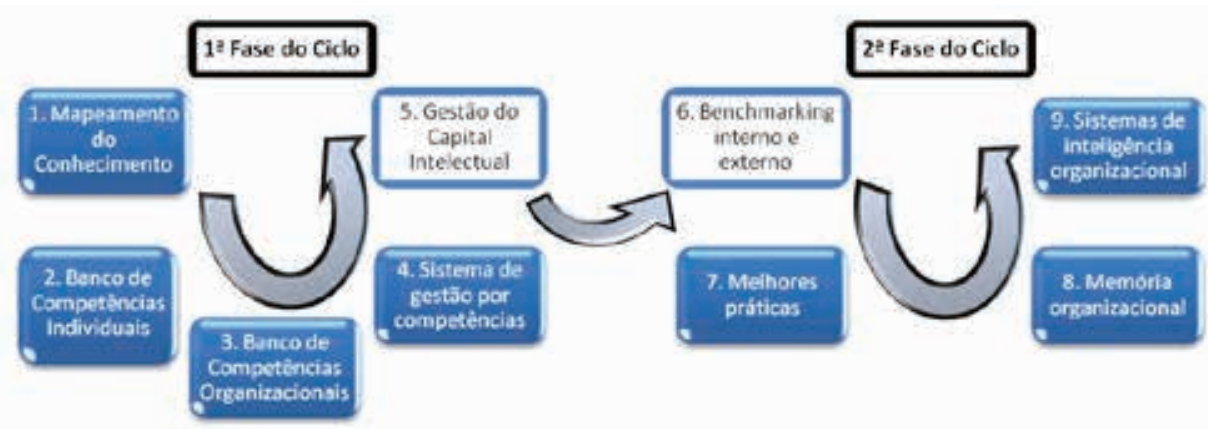

Figura 1. Ciclo de implementação de processos organizacionais em GC

Fonte: Elaborado pelos autores. 
Considera-se interessante iniciar o ciclo com a implementação da prática mapeamento do conhecimento, pois, inicialmente, deve-se elencar e mapear o que já se sabe sobre os processos, produtos, serviços e relacionamento com os clientes. Com isto, por meio desta prática, é possível fazer o levantamento dos ativos do conhecimento que a organização já possui. Após este levantamento, têm-se base para se constituir um banco de competências individuais dos servidores da instituição, que é a segunda prática do ciclo. Entende-se que o ajuntamento das competências individuais dá a possibilidade de traçar quais as competências organizacionais podem ser utilizadas para compor um banco de competências organizacionais, que é a terceira prática do ciclo. Este é apenas um exemplo de como aconteceria a implementação deste ciclo e uma forma de explicitar a dinâmica inclusa no processo, que ocorre por meio da implementação de etapas que dão suporte à ocorrência das outras.

Salienta-se que o ciclo não possui um fim determinado, pois o cumprimento de todas as etapas dá possibilidade para que o gestor, novamente, retorne a prática do mapeamento do conhecimento. Isto porque após serem implementadas todas as etapas, novos conhecimentos poderão ter sido identificados, criados, armazenados, compartilhados e aplicados; já que, para que este processo ocorra, é necessária a interação, o suporte, a troca de informações e as experiências entre os servidores.

Outro ponto importante é esclarecer a preferência de propor este ciclo dividido em duas partes integrativas. Durante a análise das ferramentas referentes aos processos organizacionais para implementação da GC, notou-se que para determinado agrupamento de ferramentas há maior aderência referente a processos e pessoas/intelecto, já para outras ferramentas a ênfase está em processos e estrutura impessoal, no entanto, todas as práticas do ciclo estão relacionadas aos processos organizacionais. Sendo assim, preferiu-se dividir o ciclo em duas fases, sendo que a primeira fase coloca o mapeamento do conhecimento como primeira prática, que faz referência à identificação de ativos do conhecimento relacionado a pessoas, já na segunda fase, o Benchmarking é posto como a prática que irá identificar os ativos do conhecimento nos processos referentes à estrutura impessoal.

É interessante notar que na primeira vez que o gestor for implementar o ciclo em sua instituição, todas as fases, incluindo o mapeamento do conhecimento e 
Benchmarking devem ser completados, para que não haja brechas na identificação de conhecimentos em processos e pessoas e na estrutura de processos da instituição. Já nas demais vezes em que o gestor for aplicar o ciclo, fica à sua disposição aplicar todo o ciclo ou somente algumas partes dele, seja para a atualização do que foi primeiramente identificado ou para difusão das ferramentas na instituição.

Assim, considerando que as práticas de GC não são substitutas às atividades de planejamento, organização, direção e controle, já instituídas nas escolas, entende-se que estas práticas são vistas como facilitadores para que o fluxo de dados, informações e conhecimentos sejam mais rápidos e auxiliem na execução destas atividades, melhorando os níveis de eficiência e também o grau de acertos na tomada de decisões. Assim, considera-se que estas práticas devem ser ajustadas às rotinas organizacionais e não o contrário.

Ao analisar as práticas, aqui traduzidas em processos organizacionais dentro do campo de pesquisa referente à GC, e considerando que várias delas dependem uma das outras para se efetivarem, pondera-se que deva haver alto grau de comprometimento na implantação destes processos principalmente por parte do gestor, já que estes processos devem ser efetivados de maneira organizada e cíclica, necessariamente carecendo de coordenação e alinhamento com as realidades culturais da organização.

\subsection{SUGESTÃO DE ROTEIRO PARA IMPLEMENTAÇÃO DO CICLO DE PROCESSOS ORGANIZACIONAIS EM GC}

Neste sentido, levando-se em conta que a correta aplicação do ciclo de processos organizacionais em GC deve ser feito de forma sistemática e coordenada, abaixo se propõe um roteiro de ação, com vistas a facilitar a implementação do ciclo de práticas organizacionais de GC. Para isto, utilizou-se como referência o trabalho de Batista et al (2005), que conceituam cada processo organizacional que orienta a implantação da GC. Ressalta-se que este roteiro serve como programa para operacionalizar e implementar as práticas sugeridas neste trabalho de forma sistemática e também, por meio de uma adequação de palavreado, descrevem-se os processos organizacionais, adequando-os ao ambiente escolar. Diz-se isto, pois 
normalmente estes gestores não possuem familiaridade com termos voltados à área da gestão.

a) Mapeamento do conhecimento: o mapeamento do conhecimento se refere ao registro do conhecimento organizacional presente na instituição escolar por meio dos: i) processos (quais os servidores são ativos na geração, identificação, compartilhamento, armazenamento e aplicação de informações e conhecimento dentro da organização); ii) serviços (quais os servidores e quais são os serviços, necessários ao funcionamento da escola, que estes realizam); iii) relacionamento (quais os vínculos entre docentes, discentes, coordenadores, funcionários técnico-administrativos, pais, comunidade etc., que permitem as atividades necessárias para uma escola acontecer). O mapeamento do conhecimento tem como utilidade prática direcionar os gestores para que estes saibam o que se sabe dentro da organização, o que dá suporte para se evitar ambiguidades, retrabalhos ou outras situações em que se investe em recursos que já se possui. A efetividade desta prática também dá apoio à realização das demais práticas pertencentes ao ciclo de implementação das ferramentas da área de processos organizacionais, que apoiam a prática da gestão do conhecimento em organizações públicas escolares.

b) Banco de competências individuais: a forma mais simples de se montar um banco de competências individuais é utilizar as informações que foram coletadas anteriormente, ou seja, no mapeamento do conhecimento, e organizá-las em uma lista on-line ou mesmo em uma planilha, referente aos servidores da escola para que fique disponível para consultas internas. A lista deve conter o perfil dos professores, coordenadores pedagógicos e funcionários técnico-administrativos, de forma que seja especificada a experiência e as áreas de funcionais de cada funcionário. Destaca-se que o banco de competências individuais ajuda o gestor a organizar os recursos humanos presentes na instituição, não numa perspectiva organizacional hierarquizada e rígida, mas em 
torno de competências dos indivíduos. Isto se torna muito útil quando é necessário reestruturar funções dentro da escola, evitando realocações desnecessárias ou mesmo problemas decorrentes do isolamento de funcionários com competências que ainda não foram amadurecidas o suficiente para realizarem seus trabalhos sozinhos. Destaca-se também, que por meio desta prática, pode-se organizar o ambiente escolar para treinar novos servidores que ainda não conhecem as rotinas, ou que ainda não possuem autonomia referente às competências para a realização do seu trabalho.

c) Banco de competências organizacionais: depois de organizadas em uma lista, elencadas e detalhadas as competências individuais dos funcionários da escola, tem-se a possibilidade de analisar as competências de cada funcionário e reconhecer as competências gerais da organização, num banco de competências organizacionais. Para isto, pode-se utilizar de outra lista, de modo a descrever quais as equipes detentoras de determinado conhecimento, quais as equipes se destacam, em nível de eficiência, em determinadas situações e quais as relações comumente estabelecidas entre as equipes para se resolver determinados tipos de problema. Uma vez que se tenha ciência destas relações, pode-se traçar um panorama, desta vez não somente das competências de cada funcionário, mas em torno das competências das equipes, que quando se juntam, potencializam suas capacidades por meio da soma de suas competências, o que gera maior eficiência nos processos. Desta maneira, ficam claros aos funcionários da instituição quais os relacionamentos entre os grupos de funcionários que podem servir como fontes de consulta em situações desconhecidas ou que demandam de certas especificidades de conhecimento interdisciplinar para resolver eventos incomuns.

d) Sistema de gestão por competências: uma vez implementado o banco de competências individuas e organizacionais, parte-se para algo mais complexo, entretanto, que pode ajudar a escola cumprir com sua função referente à efetividade social e desenvolvimento social. 
Em um nível mais estratégico, a gestão baseada nas competências: i) determina as competências essenciais requeridas da organização para que sua missão seja cumprida ii) avalia a capacitação interna em relação aos domínios correspondentes a essas competências e, por fim, iii) define os conhecimentos e as habilidades necessários para superar as deficiências e se chegar ao nível proposto na missão e na visão da escola. Neste processo, se determinadas competências forem encontradas em um setor e ausentes em outro, medidas necessárias para superar estas deficiências serão traçadas, e soluções serão buscadas, quer pelo compartilhamento interno de informaçóes e conhecimentos, quer por treinamentos e atualizações fornecidas por outras instituições externas ao ambiente escolar.

e) Gestão do capital intelectual: considerando que ativos intangíveis são recursos disponíveis no ambiente da escola, estando presentes na mente dos servidores técnico-administrativos, docentes, discentes, pais e comunidade, entende-se que estes recursos podem apoiar os processos de gestão, por meio da tomada de decisão. A prática gestão do capital intelectual dispóe ao diretor e/ou pedagogo da instituição, a possibilidade de não ficarem restritos somente aos benefícios que o sistema de gestão por competências traz à escola. Neste sentido, esta prática expande os limites circunscritos anteriormente e traz outros usuários da instituição, melhor definidos como os discentes e seus respectivos pais, ao papel de fornecedores de informaçóes e conhecimentos aos gestores das instituições. A prática se dá por meio da identificação não somente dos recursos intangíveis, dos funcionários, mas também dos agentes que utilizam os serviços da instituição. O capital intelectual pode ser expresso por know-how, ou seja, conhecimentos tácitos e explícitos e experiências culturais, profissionais e pedagógicas presentes na mente dos indivíduos. Assim, para que seja possível identificar e capturar estes conhecimentos propõe-se o uso de ferramentas específicas, como questionários ou entrevistas. Neste processo, o essencial é procurar capturar aqueles conhecimentos que normalmente são difíceis de identificar e mensurar, 
mas que podem gerar níveis maiores de eficiência. Para que não haja problemas quanto ao uso indevido destes conhecimentos pelos agentes participantes da instituição escolar, é necessário que seja estabelecida pela própria escola uma política reguladora da propriedade intelectual.

f) Benchmarking interno e externo: assim como na primeira fase do ciclo, o mapeamento do conhecimento foi fundamental para dar base à ocorrência de outras práticas e também evitar retrabalhos, servindo como indicador referente aos conhecimentos já presentes na instituição, o Benchmarking marca o início da segunda fase do ciclo. Esta prática serve como direcionadora para a busca sistemática de melhores referências, podendo-se comparar os processos, produtos e serviços presentes na própria escola, com os de outras. O ideal para esta prática é que sejam estabelecidos padrões de comparação. Para isto, recomendase o uso de indicadores (ex: ranking de notas das escolas na Prova Brasil etc.), número de aprovações/reprovação/evasão de alunos, quantidade de recursos alcançados por escolas para intervenções sociais junto ao município, competências individuais e organizacionais, utilização de ferramentas pedagógicas, novas tecnologias educacionais, processos organizacionais utilizados pelos gestores etc. O sentido norteador desta prática é comparar os índices, práticas, competências e processos de uma escola com o de outras, sejam elas privadas ou públicas, possibilitando estudos de caso, palestras e atividades de integração entre diferentes escolas para difusão destas práticas.

g) Melhores práticas: uma vez identificadas, por meio do Benchmarking, as ferramentas, atividades, processos, competências e práticas presentes em outras instituições escolares, que não são efetivas no dia a dia escolar e nem na agenda da instituição local, sugere-se que, por meio de um planejamento criterioso, se procure identificar quais as práticas, competências e processos que possibilitaram com estas estivessem mais bem colocadas nos indicadores postulados na prática anterior. Desta forma, este tipo de iniciativa refere-se à identificação, e logo a após a difusão, das práticas que trazem maiores níveis de eficiência e eficácia na realização de uma tarefa ou na solução de um problema. 
h) Memória organizacional: para que as melhores práticas não se tornem diluídas com o tempo e cada vez mais ausentes da rotina das escolas, sugere-se que, conexo à difusão das melhores práticas, deverá ser feito o registro do conhecimento organizacional adquirido sobre processos, produtos, serviços, competências etc. Este procedimento é denominado de memória organizacional, a qual serve como prevenção ao abandono das melhores práticas e também como base para que seja feito o registro de lições aprendidas, expressas por meio de relatos de experiências em que se registra o que aconteceu, o que se esperava que acontecesse e o que foi aprendido durante determinada circunstância. Neste processo, a gestão do conteúdo que compõe a memória organizacional, deverá ser feita periodicamente, para manter atualizadas as informações, as ideias, as experiências, as lições aprendidas e as melhores práticas que foram documentadas. Para isto, destaca-se constantemente a revisita a estes repositórios, para que além de preservadas e atualizadas as boas práticas, sejam registradas as falhas de projetos e processos anteriores, para que sirvam de balizadores à ação dos gestores.

i) Sistemas de inteligência organizacional: como última prática deste ciclo, destaca-se o sistema de inteligência organizacional, o qual é voltado à transformação de dados e informações em inteligência com o objetivo de apoiar a tomada de decisão. Sabendo-se que as escolas utilizam recursos públicos para sobrevivência e manutenção, é dever o gestor escolar zelar pela eficiência na utilização destes e, para isto, esta prática se mostra bem funcional, pois apoia justamente a tomada de decisão. Entretanto, para uma eficiente operacionalização do sistema de inteligência organizacional será necessária a construção e constante consulta a um repositório de conhecimentos, informações e dados, o que em outras palavras poderia se denominar de memória organizacional, mantida ativa por meio da constante alimentação, atualização e descarte de ativos tangíveis e intangíveis. 


\section{CONSIDERAÇÕES FINAIS}

Assim, compreendendo que vários fatores poderiam ser levantados como entraves à educação no Brasil, esta pesquisa preferiu tratar especificamente do problema relacionado à gestão educacional. Deste modo, percebendo que a GC tem proporcionado às organizações maior eficiência na utilização de seus recursos e, considerando que o gerenciamento do conhecimento envolve gerir pessoas, práticas e normas organizacionais, acredita-se que por meio da GC, especificamente referente aos seus processos organizacionais, pode-se promover a melhoria da qualidade do ensino, pelo compartilhamento de experiência e aplicação dos conhecimentos no nível da gestão escolar. Esta discussão lança luz sob o fato de que a qualidade da educação está positivamente ligada aos processos de gestão da própria instituição e que a administração no contexto da educação é intrínseca à própria prática educativa.

Deste modo, o objetivo desta pesquisa é descrever como as práticas da GC, alinhados à área de processos organizacionais, promovem a melhoria da qualidade do ensino pelo compartilhamento de experiência e aplicação dos conhecimentos no nível da gestão escolar. Para isto, propôs-se um ciclo de implementação de processos organizacionais em GC, especificamente para instituições de ensino público.

Percebendo que o ciclo não se esgota pelo uso, pois, durante a implementação deste novos conhecimentos poderão ser identificados, criados, armazenados, compartilhados e aplicados serão necessários processos de interação, suporte, troca de informações e experiências entre os servidores para operacionalizá-lo. Como fator importante, citou-se que estas práticas deverão ser vistas como facilitadoras, sendo ajustadas às rotinas organizacionais e não o contrário, necessariamente carecendo de coordenação e alinhamento com as realidades culturais da organização. Anexo a esta proposta, sugeriu-se um roteiro de implementação do ciclo, que descreve como se pode implementar estes processos, adequando-os à realidade do ambiente escolar público. Diz-se isto, pois normalmente os gestores das instituições escolares públicas não possuem familiaridade com os termos voltados à área da gestão do conhecimento.

Assim, por meio do roteiro de implementação do ciclo de processos organizacionais da GC, desenvolveu-se uma metodologia para apoiar os gestores 
destas instituições para que promovam e operacionalizem estas práticas. Tal roteiro foi desenvolvido a partir do entendimento de que estas ferramentas são vistas como facilitadoras para que o fluxo de dados, informações e conhecimentos seja mais rápido e auxilie a execução de atividades pertinentes a este tipo de organização. Portanto, por meio destas sugestões referentes ao ciclo e de seu respectivo roteiro de implementação, conseguiu-se agenciar contribuições para a área educacional, no sentido de resolver os problemas específicos da gestão escolar pública. No entanto, faz-se importante reafirmar que a sugestão do roteiro tem o intuito apenas de incentivar debates acadêmicos de como solucionar os problemas relacionados à gestão escolar por meio das práticas de GC relacionadas ao processo organizacional.

\section{REFERÊNCIAS}

AZIZ, K.A. Application reality of knowledge management processes practice in leaning resources centres: case study of learning resources centres in Makkah alMukarramah schools in Saudi Arabia. Procedia Computer Science, v. 65, 2015.

BATISTA, F.F.; QUANDT, C.O.; PACHECO, F.F.; TERRA, J.C.C. Gestão do conhecimento na administração pública. Brasília: Ipea, 2005. 125p. (Texto para Discussão, n. 1095).

BATISTA, F.F. (Org.) Experiências internacionais de implementação da gestão do conhecimento no setor público. Rio de Janeiro: Ipea, 2016.

\section{BATISTA, F.F. Modelo de gestão do conhecimento para a administração pública} brasileira: como implementar a gestão do conhecimento para produzir resultados em benefício do cidadão. Brasília: Ipea, 2012.

CAVALCANTI, M.; GOMES, E. Inteligência empresarial: um novo modelo de gestão para a nova economia. Produção, v.10 n.2, p.53-64, maio 2001.

COELHO, A.D.S. Gestão escolar e inovação: novas tendências em gestão escolar a partir das gestão escolar e inovação. 2011. Tese (Doutorado em educação) - 
Pontifícia Universidade Católica (PUCSP), São Paulo, 2011.

DAMACENO, R.S. Ambiência para gestão do conhecimento nas escolas públicas de Taguatinga. 2013. Dissertação (Mestrado em Gestão do Conhecimento e Tecnologia da Informação) - Universidade Católica de Brasília, 2013.

DOURADO, L.F. Gestão da educação escolar. Brasília: Universidade de Brasília, Centro de Educação a Distância, 2006.

FRANCINI, W.S. A gestão do conhecimento: conectando estratégia e valor para a empresa. RAE-eletrônica, v.1 n. 2, jul./dez, 2002.

GUIMARÃES, S.K. Empreendedorismo intensivo em conhecimento no brasil. Caderno CRH, Salvador, v. 24, n. 63, p. 575-591, set./dez. 2011.

LASTRES, H.M.M. Informação e conhecimento na nova ordem mundial. Ci. Inf., Brasília, v. 28, n. 1, p. 72-78, jan. 1999.

LIBÂNEO, J.C. O sistema de organização e gestão da escola, UNESP, 2010. Disponível em: $<$ http://www.acervodigital.unesp.br/bitstream/123456789/32/3/ LDB_Gest\%C3\%A3o.pdf>. Acesso: 05 set. 2016.

LÜCK, H. Gestão escolar e formação de gestores. Em aberto, Brasília, v. 17, n. 72, p. 1-195, fev.jun. 2000.

LÜCK, H. Perspectivas da gestão escolar e implicações quanto à formação de seus gestores. Em Aberto, Brasília, v. 17, n. 72, p. 11-33, fev./jun. 2000.

MASSARO, M.; DUMAY, J.; GARLATTI, A. Public sector knowledge management: a structured literature review. Journal of Knowledge Management, v. 19, n. 3, p. 530-558, 2015.

PORÉM, M.E.; SANTOS, V.C.B.; BELLUZZO, R.C.B. Vantagem competitiva nas empresas contemporâneas: a informação e a inteligência competitiva na tomada de decisões estratégicas. Intexto, Porto Alegre, n. 27, dez. 2012.

PRODANOV, C.C.; FREITAS; E.C. Metodologia do trabalho científico: métodos e 
técnicas da pesquisa e do trabalho acadêmico. 2. ed. Novo Hamburgo: Feevale, 2013. SILVA, E.L.; MENEZES, E. M. Metodologia da pesquisa e elaboração de dissertação. 4. ed. Florianópolis: UFSC, 2005

SINGH, R. M.; GUPTA, M. Knowledge management in teams: empirical integration and development of a scale. Journal of Knowledge Management, v. 18, n. 4, p. 777-794, 2014.

SMUTS, H.; SMUTS, A.V.D.; LOOCK, M.; KOTZÉ, P. A framework and methodology for knowledge management system implementation. In: ANNUAL CONFERENCE OF THE SOUTH AFRICAN INSTITUTE OF COMPUTER SCIENTISTS AND INFORMATION TECHNOLOGISTS, 2009. Proceedings... Vanderbijlpark, Emfuleni, South Africa, oct. 2009.

SOUSA, A.D.D. As práticas de gestão de conhecimento nas organizações públicas: o ministério da justiça. 2002. Dissertação (Mestrado em Gestão Empresarial Pública) - Escola Brasileira de Administração Pública - EBAP, Fundação Getúlio Vargas, Rio de Janeiro, 2002.

SOUZA, A.M.; KURTZ, D.J. Análise de modelos para a gestão do conhecimento organizacional: o caso serviço social da indústria-SESI/PE. International Journal of Knowledge Enginnering and Management, Florianópolis, v.3, n.6, p. 64-88, jul./ nov. 2014.

WITTMANN, L. C. Autonomia da escola e democratização de sua gestão: novas demandas para o gestor. Em Aberto, Brasília, p. 88-96 fev./jun. 2000.

Recebido em: 30 de novembro de 2016 Aceito em: 19 de abril de 2017 